\title{
GCU
}

Glasgow Caledonian

University

University for the Common Good

\section{The effect of cosmetics packaging design on consumers' purchase decisions}

Abdelazim Mohammed, Nada Bahgat; Garcia Medina, Irene; Gonzalez Romo, Zahaira

Published in:

Indian Journal of Marketing

DOI:

10.17010/ijom/2018/v48/i12/139556

Publication date:

2018

Document Version

Publisher's PDF, also known as Version of record

Link to publication in ResearchOnline

Citation for published version (Harvard):

Abdelazim Mohammed, NB, Garcia Medina, I \& Gonzalez Romo, Z 2018, 'The effect of cosmetics packaging design on consumers' purchase decisions', Indian Journal of Marketing, vol. 48, no. 12, pp. 50-61.

https://doi.org/10.17010/ijom/2018/v48/i12/139556

\section{General rights}

Copyright and moral rights for the publications made accessible in the public portal are retained by the authors and/or other copyright owners and it is a condition of accessing publications that users recognise and abide by the legal requirements associated with these rights.

Take down policy

If you believe that this document breaches copyright please view our takedown policy at https://edshare.gcu.ac.uk/id/eprint/5179 for details of how to contact us. 


\title{
The Effect of Cosmetics Packaging Design on Consumers' Purchase Decisions
}

\author{
* Nada Bahgat Abdelazim Mohamed \\ ** Irene García Medina \\ *** Zahaira González Romo
}

\begin{abstract}
This research provided new helpful insights for cosmetics marketers about their consumer preferences regarding visual elements of their hairstyle, skin care, and makeup products. A quantitative research approach was adopted using the survey research design and used a questionnaire tool to achieve the research objectives. Data were collected and analyzed from 130 female cosmetics respondents. Previous research studies from academic journals, articles, and books were also used as secondary resources. The findings showed that cosmetics consumer behaviour was, in fact, affected by the visual elements of the cosmetics package designs and thus affected the consumers' purchase intentions. Moreover, material and colours of the hairstyle, skin care, and makeup products packages were proved to be of high importance with respect to the level of attractiveness and affected consumers' preferences.

Keywords : visual elements, cosmetics package design, mode of purchase, consumers' purchase intentions

Paper Submission Date : May 8, 2018 ; Paper sent back for Revision : October 7, 2018 ; Paper Acceptance Date : November 16, 2018
\end{abstract}

$\mathrm{T}$ he purpose of this research is to provide an understanding of the impact of the visual elements of cosmetic package designs on consumers' buying intentions, with an emphasis on the influence of the mode of purchase (in store/online) on consumers' perception of product packaging design. The importance of the results of this study lies in the opportunity it gives marketers to make strategic changes regarding their product package design in relation to the mode of purchase. The research aims to provide a clear understanding about the effect of in store and online shopping on the influence of product packaging design towards consumers' purchase processes. Moreover, it suggests how to create an attractive package design based on consumers' preferences, which is an effective marketing tool at the point of purchase that encourages consumers to make the purchase decision.

\section{Research Background}

First impressions and physical appearances also matter in the product choices of consumers as people normally feel the urge to obtain objects that have appealing appearances (Adofo, 2014). According to Cholewa - Wójcik and

* Researcher at Business Management Department, Glasgow Caledonian University, Cowcaddens Road, Glasgow G4 0BA, Scotland,UK.E-mail:NMOHAM202@caledonian.ac.uk

** Lecturer at Business Management Department, Glasgow Caledonian University, Cowcaddens Road, Glasgow G4 0BA, Scotland,UK.E-mail: Irene.Garcia2@gcu.ac.uk

*** Lecturer at Communication Department, Universitat Internacional de Catalunya, Immaculada 22, 08017 Barcelona, Spain.E-mail :zfgonzalez@uic.es 
Świda (2015), "[...] the visual aspect of the packaging is a certain form of language that should lead to attracting the consumer's attention to the product, then decode the message, generate interest, trigger purchase decision, and leave a long - lasting positive connotation" (p. 7). The aim of this study was to analyze the consumer perception of the visual aspects of selected chocolate collectible wrappers with the use of the eye - tracking method. The subsidiary aim was to examine the reactions and acceptance of modern consumers to visual aspects of the chocolate wrappers offered in the market in the 1970s and the 1980s of the 20th century, in which the graphic design was not directly connected with the product.

When consumers observe a package design of a product, they not only form an impression about the packaging design, but also about the product and the brand as well (Grundey, 2010). In many cases, consumers' value judgements of products are based on attractive packaging designs; hence, a link is formed between an attractive package and satisfied/well-thought purchase decisions (Lo, Tung, \& Huang, 2013). Packaging acts as a brand identifier to consumers ; it also serves as a powerful marketing tool that requires the same focus, attention, and techniques used in other forms of marketing to get the maximum benefit of combining all tools together (Simmonds \& Spence, 2016).

\section{Review of Literature}

(1) Packaging Plays a Powerful Role as a Marketing Tool : The marketing role of product packaging in recent literature has been intensively mentioned, and so is the usage of product packaging within the marketing communications strategies of brands. For instance, Altmann (2014) suggested that the delivery of the product ('packaging') is just as vital as the house it comes from (the 'brand'). From a marketing perspective, a number of studies discussed the indicators of success of a brand through the strength of its marketing strategy, and in particular, packaging design strategies (Ahmed, Parmar, \& Amin, 2014 ; Gelici - Zeko, Lutters, Klooster, \& Weijzen, 2012 ; Mohebbi, 2013 ; Magnier, Schoormans, \& Mugge, 2016) as it is considered an effective form of instore advertising, which has proven to be of even higher efficiency than regular advertising forms due to enhancing the product at point of purchase, which triggers the consumer buying intentions in addition to promoting the product every time the consumer uses it (Altmann, 2014).

Moreover, packaging has an influential role as a sales assistant within stores (Grant, Barichello, \& Fitzpatrick, 2015) and is regarded as an important component of our modern lifestyle, and a significant element of the branding process (Shekhar \& Raveendran, 2013). Grant et al. (2015) also identified the package design to be the "silent salesman" which attracts consumers more than other communication tools. The previous studies have a clear correlation with Rundh's (2013) study which indicated the importance of the usage of package designs as a sales person on shelves that identifies a brand. Gelici - Zeko et al. (2012) suggested the use of product packaging to exploit its influence in generating intended consumers' expectations towards the product and the brand overall.

These intended expectations arise with colour, material shape, words, and images of the product packaging that gives the product a semiotic significance. Rundh (2013) added to Gelici - Zeko's study that expectations of consumers do not end by the purchase decision, however, it even extends to later experiences of consumers that get aroused later during the usage of the product package for other purposes after the purchase is done and the product is used.

The personality of a product is shaped by its package design which is correlative with the brand's overall identity as the package design displays the uniqueness of a product and a brand. Once a consumer is attracted by a certain package design and thus the brand, an interpretation of the brand identity is shaped, and hence, the product packaging could be the shortest route to forming the brand equity (Wardy, Chonpracha, Chokumnoyporn, Sriwattana, Prinyawiwatkul, and Jirangrat, 2017).

Packaging plays a huge role in forming brand preferences. Baruk and Iwanicka's (2016) latest study agreed with the previous studies and added that due to the constant consumption era, consumers' expectations are becoming 
more and more of high importance as these are never fully met. This provides marketers with a great benefit, which leads to creating rapid market offers that could benefit consumers by meeting their rapidly changing needs and benefit their brands as well.

Product packaging design was declared as the most important factor that interacts with consumers face-to-face and increases a brand's positive image, and thus increases the retail performance (Aday \& Yener, 2014). Therefore, marketers have to declare the correct packaging elements that target their consumers emotionally and mentally. According to Lee and Hoffman (2016), packaging elements can be categorized in two main categories : visual and informational elements. The visual elements consist of graphics, colours, fonts, size, and shape of the package. The informational elements are the facts labelled on products regarding their usage and about technologies/ingredients used in the package or the product (Lo et al., 2013).

Baruk and Iwanicka (2016) found that the attraction caused by the likeness of particular colours of a package design was usually a strong determination of the purchase decision, whether positive or negative. It was concluded that the colour of a brand is directly related to the brand name and brand equity (Aday \& Yener, 2014).

The creation of new innovative package designs helps in shaping a differentiation from the competitors of a brand. Gelici - Zeko et al. (2012) added that within the competitive environment that is faced by marketer's nowadays, the most important marketing tool to overcome this challenge is the usage of the product package design to persuade people at the point of purchase in stores where products are presented on the shelves.

Consumers become more involved with the packaging of a product as they interact with it to view information or to read instructions regarding the product (Gelici - Zeko et al., 2012). Marketers benefit from the role of packaging in maintaining the positioning of a product due to the minimal costs of this role, as advertising expenses cost more.

Another important role packaging performs through its positioning role is the impact packaging has on branding (Mohebbi, 2014). Branding is a company's most important assets, the value added to the name of a brand is what all companies aspire to achieve. Recent studies agreed upon the several roles of packaging in marketing ranging from creating awareness using attractive innovative designs, identifying brand, and creating its competitive edge (Rundh, 2013).

(2) Packaging Designs of Cosmetics and Their Influence : Given the nature of this study, which focuses on the effect of the cosmetic products on consumer behaviour and the effect of the mode of purchase, relevant studies on cosmetic packaging were reviewed. However, the marketing literature lacks in-depth studies regarding this topic. The focus has been on the packaging views in general and on the consumer rather than the unique nature of packaging (Simms \& Trott, 2010). However, the effect of beauty packaging design particularly is very powerful as it acts as an advertisement of the product inside the pack, the beauty products' packages link the design to the brand image and the consumer lifestyle. For instance, packages of certain makeup colours and hair products usually set brands apart and are a major factor of differentiation among the millions of beauty products (Penning, 2012).

In the cosmetics market, hair products or skin care products compete in similar package forms, and the differentiation is harder for marketers for these products than it is for other packages. This is because some shampoos, for instance, are already different in their components and that a package design would not add a great distinction. However, a study by Penning (2012) argued that due to the fact that the cosmetics products, particularly hair and skin are usually different, and this was why a unique package design that stands out is crucial to communicate its distinction to consumers.

Few studies revealed the effects of cosmetics package design on consumer behaviour. For instance, Khan's (2015) findings stated that consumers were affected by the attractiveness of the packaging and were influenced by the package design due to the colours of the packaging of nail polish products, which influenced the consumer buying intentions and perception of the brand which was later supported by other studies (Javed \& Javed, 2015; Rundh, 2016 ; Yang \& Lee, 2016). According to Azeema, Jayaraman, and Kiumarsi (2016), the packaging of 
perfumes played a "vital role" in the consumers' preference and attraction, but curiously, they found that there was no discrimination between branded and non-branded perfumes as long as the quality was maintained.

However, other studies argued that the importance of informational elements on the package design of cosmetics products was as important as the visual elements (Mohebbi, 2014 ; Silayoi \& Speece, 2007). For instance, packaging information on skincare products provides consumers with essential information regarding the usage, ingredients, and other information.

\section{Research Objectives}

(1) To identify visual aesthetic elements of cosmetics packaging design that influence consumers' buying behaviours.

(2) To identify whether consumers' perceptions of the aesthetic elements of cosmetics packaging design were influenced by the mode of purchase (in store/ online).

(3) To consider the implications and differences of the mode of purchase - whether in store or online on consumers' perceptions towards the aesthetic elements of cosmetics packaging design.

(4) To provide insights into cosmetics manufacturers and marketers about the elements of cosmetics packing design that attract consumers in store and online.

\section{Methodology}

This research aims to deepen the understanding of the effect of the visual elements of cosmetics packaging designs and the mode of purchase on consumers' purchase decisions. A total of 130 qualified questionnaires were collected and analyzed using the online survey over a period of two weeks in March 2017 due to the fact that the questionnaire was designed only for women cosmetics consumers which demanded more time. This gave a total sample size for this study of 130 questionnaires, which is an applicable sample size for this particular topic, which aimed to deepen the understanding of existing theories (effect of packaging designs) in relation to specific situations (mode of purchase).

The survey was the only quantitative method used as this study applied the mono - quantitative method. The questionnaire consisted of 28 questions, and the results of the questionnaires helped to reach the main aim and objectives of the study and provide suggestions for cosmetics marketers to help improve consumers' positive perceptions of their brands in the future.

\section{Analysis and Results}

The findings of the survey are presented as per the thematic structure method; the findings are divided into three main themes. The findings are also analyzed and compared to previous research outcomes and are finally analyzed to form possible rational speculations.

(1) Consumer Behaviour with Reference to Cosmetics : The questionnaire was designed to discuss a very important and vital issue, which is the consumer behaviour of cosmetics shoppers in particular. This issue was implemented through the design of questions $(4,5,8,9,10$, and 18). In Question 4, the respondents were asked about the time they usually spent during shopping in a makeup store, 46.88\% said that they spent from $15-20$ minutes shopping, and $37.50 \%$ said that they spent more than 20 minutes in the store.

In addition, when consumers were asked whether they were capable of differentiating cosmetics brands just 
Table 1. Most Attractive Aspects of Products (Questions 8, 9, and 10)

\begin{tabular}{|c|c|}
\hline Categories & Results \\
\hline Hairstyle & $\begin{array}{l}\text { 44.96\% chose the quality aspect as the most attractive, while } 38.76 \% \text { chose the packaging, } 13.18 \% \text { chose } \\
\text { convenience, and only } 3.10 \% \text { chose price as the most attractive aspect. }\end{array}$ \\
\hline Skin care & $\begin{array}{l}44.96 \% \text { of the respondents said they valued the quality of the product as the most attractive aspect, and } \\
38.76 \% \text { of the respondents chose product packaging design, followed by a percentage of } 10.85 \% \\
\text { respondents who preferred convenience, and finally, } 5 \% \text { chose price as the most attractive aspect. }\end{array}$ \\
\hline Makeup & $\begin{array}{l}41.86 \% \text { chose quality and } 39.53 \% \text { of the respondents chose product packaging. A percentage of } \\
10.85 \% \text { chose convenience and finally, } 7 \% \text { of the respondents chose price as the most attractive aspect. }\end{array}$ \\
\hline
\end{tabular}

from their packaging designs in Question 18, the majority of the respondents (with a percentage of 88.37\%) said that they could differentiate products depending only on their packaging designs. While the majority of the respondents confirmed their ability to identify a brand using only the packaging design, they also said that they spent more than 15 - 20 minutes when making their purchase decisions during their cosmetics shopping.

These also echo the findings of Adofo (2014), who stated the importance of packaging regarding the moment of purchase behaviour of the consumer. As consumers tend to generate evaluations of the products while viewing them on shelves next to competitors, the packaging design is the most powerful tool to persuade consumers with a certain product given its brand identifier and differentiator roles (Karimi, Mahdieh, \& Rahmani, 2013).

Question 5 of the questionnaire asked respondents of the possibility in which they entered the store to buy a certain product, however, ended up buying other products as well; the results show that $54.26 \%$ of the respondents stated that it occurred quite often while shopping. In addition, a percentage of $43.41 \%$ respondents stated that the occurrence of such an act happens always while shopping in a cosmetics store. Moreover, Questions 8, 9, and 10 asked consumers about the aspect they viewed as the most attractive regarding a hairstyle, skin care, and makeup product, respectively, and all results are presented in the Table 1.

These results associated together support the idea of the powerful effect of packaging that could be used by marketers to generate more impulse purchases from consumers. Considering the results of Questions 8, 9, and 10, respectively, the product packaging design was chosen with high percentages ranging between $38.76 \%, 32 \%$, and $39.53 \%$ of respondents regarding their opinion of the most attractive aspect of a hair style, skin care, and makeup product, respectively. These percentages suggest that product packaging design is a very attractive aspect that could trigger consumers to purchase the product, and packaging is one of the most vital factors in forming the brand identity as it tells the story and defines a brand.

These findings are in line with previous studies that identified packaging as one of the powerful triggers of impulse shopping, for instance, Yang and Lee (2016) stated that above 50\% of the consumers switched between brands due to in-store marketing. In addition, Rundh's (2005) findings stated the possibility of product packaging design to trigger four types of impulse buying such as reminder impulse buying or suggestion impulse buying when consumers thought they had already determined what to purchase, however, after entering the store, they were triggered to purchase other products as well.

(2) The Effect of Visual Elements : The questions were designed to provide an understanding of the value of the visual elements such as the package colour and material. Questions 6 and 7 in the questionnaire were designed to ask participants about their own opinion regarding the importance of the visual elements of the cosmetics package design. For instance, Question 6 asked consumers about the most attractive factor in a cosmetics product design ; $40.31 \%$ said that the package material was the most attractive factor, while $36.43 \%$ said that the colour of the package attracted them the most, $12.40 \%$ said that the size and shape of the package attracted them the most, and only $10.58 \%$ said that the image placed on the package attracted them the most.

These findings are in line with those of previous studies, which stated the importance of the material and colour 


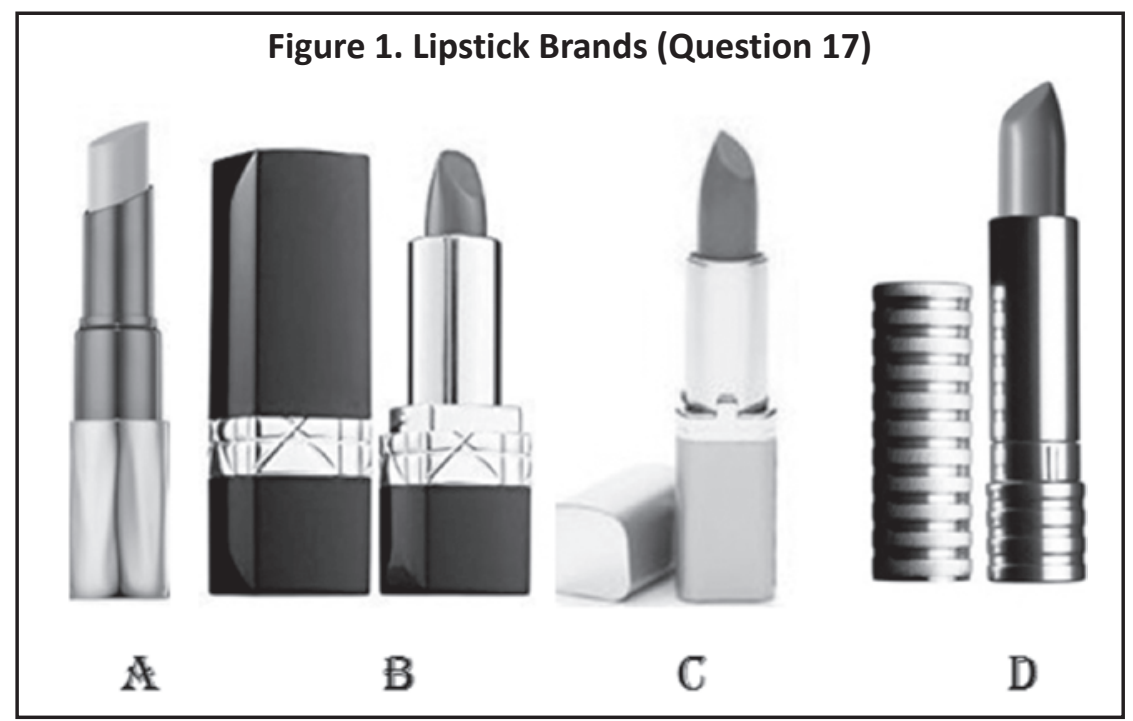

of the package design in the formation of a positive image of the product and brand in the consumers' minds (Aday \& Yener, 2014 ; Karimi et al., 2013). However, these findings contradict with those of Penning (2014), who stated the importance of consumers to view the image of the product placed on the package as it gives them a sense of assurance about the product. On the contrary, this was the least factor chosen by the respondents.

In Question 7, the respondents were asked to rate the cosmetics packaging attributes according to their importance in making their purchase decisions. Package attractiveness came at the first position, then package aesthetics, followed by package functionality in the third place. Package originality and elegance were rated forth by equal percentages. The respondents stated that the package attractiveness was the most important factor that influenced their purchase intention when they were shopping in a cosmetics store.

Question 17 of the survey asked respondents to rate four lipsticks without knowing the brands and depending just on the package design of the lipsticks. The four lipsticks shown in Figure 1 are : (A) Urban Decay lipstick with an average price of $£ 16,(B)$ Dior lipstick with an average price of $£ 25,(C)$ L'Oréal lipstick with an average price of $£ 5$, and finally, (D) Clinique lipstick with an average price of $£ 12$. Surprisingly, Figure (A) and (B) were ranked in a similar manner to be of least quality. However, Figure (B), the Dior lipstick is the most expensive lipstick shown. A possible explanation for this could be that this particular lipstick was not very popular among the young respondents, who were in majority in this study. The respondents rated the Figure (C), the L'Oreal lipstick, to be of the highest quality, although it was the least - expensive lipstick. It seems possible that this particular finding is due to the clever usage of the colour element and visual attractiveness by the brand L'Oreal as the gold colour usually transmits a high quality thorough the assumption that it looks more expensive than others. This finding is in line with Altmann's (2014) findings regarding the powerful effects of colours of the package design.

Based on Questions 6, 7, and 17, their findings reveal that the most attractive factor of a product package is the material, then the colour of the package, and the most important aspect in product package that would trigger consumers' purchase intention is the packaging attractiveness. With respect to Question 17's findings, where consumers chose the least - expensive lipstick as the highest quality lipstick due to their dependency on the package design alone, the importance of visual elements of the cosmetics package design and its effect on consumers' purchase intentions can be gauged.

Due to the importance of the material and colour of the cosmetics package design, the questionnaire had certain questions designed particularly to deepen the understanding of the effects of both elements. As mentioned before in Question 6, these were the two most attractive elements based on the respondents' answers.

First, the cosmetics packaging material of hairstyle, skin care, and makeup products was discussed in Questions 
14,15 , and 16, respectively. Plastic was the common preferred material by respondents throughout the three categories by a percentage of $61.72 \%$ in hairstyle products, $59.69 \%$ in skin care products, and $58.91 \%$ in the makeup category. The second most preferred material in the three categories was glass with a percentage of $16.4 \%$ in hairstyle and $22.48 \%$ in both of skin care and makeup categories.

These findings seem to be consistent with those of Aday and Yener (2014), who stated the fact that consumers usually tend to prefer user friendly material that is super practical in addition to its resistance to any sort of damage such as breakage. Moreover, there is a relation between Questions 14, 15, and 16 and Questions 8, 9, and 10. Convenience was chosen as the third most attractive aspect of hairstyle, skin care, and makeup products by $13.18 \%$ in hairstyle products, and $10.85 \%$ in both skin care and makeup products. These findings show the reason why plastic was chosen with a high percentage due to its convenient yet attractive look that transmits an image of a good quality product.

Consumers were asked to choose the most attractive colour for a hairstyle, skin care, and makeup product, respectively. In the hairstyle category, respondents chose brown colour as the most attractive colour (chosen by $61.24 \%$ of the respondents), white colour was chosen by respondents by a percentage of $58.91 \%$ in the skin care category, and finally, in the makeup category, $60.47 \%$ chose the black colour.

These findings might partly be explained through the psychology of colours demonstrated by Roberge (2016) in his study that clarified the usage of colours in packaging. In his study, he suggested that the brown colour, which was chosen for the hairstyle products, is usually used by companies that intend to show their products as organic, safe, and comforting to use, which is applicable for hairstyle products as consumers prefer to use organic ingredients when styling their hair.

These findings might possibly be directly related to the meaningful messages of colours, which was discussed by Javed and Javed (2015). Their study stated the importance of colours which have the capability to boost a product's sale, while the usage of wrong colours could lead to a product's failure. In addition, the influence of colours arouses the interest to purchase and motivates consumers to try other products as well.

(3) The Mode of Purchase (Online/In - Store) : Finally, yet importantly, the questionnaire was designed to tackle the mode of purchase issue to reach the objectives. The questions aimed to reveal the relationship between the mode of purchase and consumers' perception of package design of cosmetics products and the reason behind their purchase behaviours.

Interestingly, it was found that a majority of $78.91 \%$ preferred buying cosmetics in-store and $21.09 \%$ preferred buying online. Moreover, when asking respondents to agree or disagree with several statements, the results were as follows: In Question 20, a majority of 79.07\% strongly agreed with the statement that said that they felt assured when doing cosmetics shopping in-store more than online. In Question 21, a percentage of 51.56\% and 27.34\% strongly agreed and agreed, respectively with the statement that said that they got more attracted by price offers when shopping online more than in-store.

In Question 22, the respondents with a percentage of $53.91 \%$ and $27.34 \%$ agreed and strongly agreed, respectively with the statement that mentioned how consumers did not like taking risks when shopping online and preferred to buy their trusted brands.

However, surprisingly, in Question 23, which stated that consumers usually get influenced by product packaging design online, and make the purchase decisions just because of the package design, this found an agreement with a majority of $52.34 \%$ of the respondents. Finally, in Question 24, a majority of $51.16 \%$ and $35.66 \%$ respondents strongly agreed and agreed, respectively with the statement that said that they preferred buying makeup products, in particular, in-store to try on samples first.

Before getting into an in-depth analysis of the above results, it would be clearer if the other remaining questions discussing the main theme are presented. For instance, in Question 25, the respondents were asked about the most attractive visual design that could trigger them to purchase online, and Question 26 asked the exact same, however, this time for when shopping in-store. 
In the results of Question 25 (online shopping), a majority of $67.19 \%$ chose the "visualisation of product usage" element and for Question 26 (in-store shopping), a majority of 55.81\% chose an appealing appearance. Moreover, in Question 28, when respondents were asked what was the most common reason they would like to buy different brands online and in-store, $42.06 \%$ of the respondents said that it was due to the variety of products available, while $34.58 \%$ said that the most common reason was time saving.

These findings show how the vision sense of consumers is the most dominating sense, and as a result, this should be used by manufacturers in their product package designs. Hence, the findings of Question 25 that the majority of the consumers chose the most important factor as product usage is also supported by Silayoi and Speece (2007) in their study that stated the importance of presenting the packaging design visually as one of the most vital communication elements. However, when consumers were asked about the most attractive factor of a cosmetics design in-store, the majority said the appealing appearance.

\section{Discussion}

This article aims to deepen the understanding of the effect of the visual elements of cosmetics package design and the mode of purchase on consumers' buying decisions. The findings of the study were analyzed and discussed in relevance to previous research findings, and regarding the related objectives intended to achieve the main aim.

(1) Cosmetics Consumer Behaviour Regarding Packaging Attributes : The first objective of this study is to identify the visual elements of cosmetics packaging design that influence consumers' buying decisions. Based on the findings of this study, cosmetics consumers chose the material of the packaging to be the most attractive factor in a cosmetics product and the second most attractive was the colour of the package design.

Moreover, consumers rated the package attractiveness as the most important attribute of a cosmetics packaging that could affect their purchase decisions. Finally, when cosmetics consumers ranked a group of four lipsticks without knowing their brands and depending only on the packaging design, they ranked the least expensive as the highest quality because its golden packaging looked sophisticated. Thus, this finding suggests that packaging designs form an image of the brand and its quality.

Despite its exploratory nature, this study offers some insight into a new model which suggests that the usage of the correct and preferred material based on the target consumers' preference will lead to the product's attractiveness, which as mentioned above, is the most attractive attribute according to the consumers' opinions. Thus, this will lead to the formation of a positive brand image based on a perception of a high-quality product ; hence, this will lead to an increase in the purchase intentions of consumers, and finally, this will lead to the increase of sales and profits, which according to Neubauer (1973), is what business and marketing is all about.

(2) Mode of Purchase Effect on Consumers' Perceptions of the Packaging Aesthetic Elements : The second and third objectives of this study are to identify whether consumers' perceptions of aesthetics elements are influenced by the mode of purchase. Moreover, the study also attempts to consider the implications of these different effects on consumers' perceptions towards the aesthetics elements of the cosmetics package design. This study has shown that in fact, consumers' perceptions of the visual elements of the cosmetics package design are different when they shop online and in-store.

Based on the previous analysis, consumers stated that the most attractive visual design that influences their purchase decisions was the presence of the visualization of the product usage on the package. On the other hand, their most preferred visual design attribute when shopping in-store was the appealing appearance of the product that attracted them.

Hence, this study extends our knowledge of the influence of the visual designs based on the different implications of the mode of purchase. The consumers stated that they felt more assured when shopping in-store and this can be 
explained as a reason why they preferred a visualization of the product usage online to feel more assured about their purchase decisions.

\section{Managerial Implications}

The fourth and last objective of this study is to provide insights to cosmetics manufacturers and marketers about the elements of cosmetics packaging design that attract consumers in-store and online. This study shows how the mode of purchase could affect consumers' perception of the attractiveness and thus highlights the importance of the visual elements of cosmetics designs.

Moreover, this study has provided other insights such as the preferred colour and material of the package design of hairstyle, makeup, and skin care products. In addition, the findings of this study show that cosmetics consumers preferred to shop so that they could see the products and try out samples of the same.

Based on the findings of this study, it can be concluded that the visual elements of cosmetics packaging have proven to be of great importance to consumers while they are shopping either in-store or online. From this, visual packaging attributes such as material, colour, appealing appearance, and visualization are identified as the most influential attributes that affect consumers' purchase intentions.

\section{Limitations of the Study and Recommendations for Future Research}

A possible weakness of this study is that only 130 respondents were consulted. However, due to the time restraints, this sample frame was the most applicable to form a generalization for the purpose of writing this article. Although the objectives and main aim of this study are achieved, possibly another limitation is the mono-method research strategy used in this study, which depended only on the survey strategy using the questionnaire tool. Other research directions might be used in the future to provide a diverse analysis that depends on the variation of cosmetics consumers' opinions based on a qualitative method or a mix of both quantitative and qualitative methods.

Due to the nature of qualitative research, it usually provides a more in-depth analysis and demonstrates the reasons behind the answers provided in the questionnaire. However, given the time and budget of this study, it could be argued that the sample size and the mono-method research strategy could be used to form adequate generalized findings.

The suggestions for future research include : (a) the use of a mixed methodology of both quantitative and qualitative research strategies; (b) the use of a cross-cultural study that would determine if these findings differ from one country/ culture to another ; (c) the use of the longitudinal time horizon instead of a cross-sectional design. This would provide a long period for them to observe the relationship between the visual elements of cosmetics design, the mode of purchase, and cosmetics consumers' purchase intentions.

Continued efforts from cosmetics marketers and manufacturers are needed to ensure the effectiveness of their packaging designs and the extent to which these package designs influence consumers' perceptions. In addition, the importance of visual elements and how they relate to the mode of purchase could be taken into consideration by marketers when designing their hairstyle, makeup, and skin care products.

\section{References}

Aday, M., \& Yener, U. (2014). Understanding the buying behaviour of young consumers regarding packaging attributes and labels. International Journal of Consumer Studies, 38 (4), 385 - 393. 
Adofo, A. (2014). The effect of beauty product packaging on consumer buying decision. The Business and Management Review, 5 (3), 14 - 21.

Ahmed, R., Parmar, V., \& Amin, M. (2014). Impact of product packaging on consumer's buying behaviour. European Journal of Scientific Research, 120 (2), 145 - 157.

Altmann, C. (2014). The whole package : Packaging and product aesthetics. Global Cosmetics Industry Magazine, $182(5), 50-52$.

Azeema, N., Jayaraman, K., \& Kiumarsi, S. (2016). Factors influencing the purchase decision of perfumes with habit as a mediating variable: An empirical study in Malaysia. Indian Journal of Marketing, 46 (7), 7 - 22. doi:10.17010/ijom/2016/v46/i7/97124

Baruk, A., \& Iwanicka, A. (2016). The effect of age, gender and level of education on the consumer's expectations towards dairy product packaging. British Food Journal, 118 (1), 100 - 118.

Cholewa - Wójcik, A., \& Świda, J. (2015). A study and assessment of selected elements of the visual aspect of collectible chocolate packaging with the use of eye-tracking method. Indian Journal of Marketing, 45 (7), 7 - 18. doi:10.17010/ijom/2015/v45/i7/79922

Gelici - Zeko, M.M., Lutters, D., Klooster, R.T., and Weijzen, P. (2012). Studying the influence of packaging design on consumer perceptions (of dairy products) using categorizing and perceptual mapping. Packaging Technology and Science Journal, 26(4), 215 - 228.

Grant, T., Barichello, V., \& Fitzpatrick, L. (2015). Accounting the impacts of waste product in package design. Procedia CIRP, 29, 568 - 572.

Grundey, D. (2010). Functionality of product packaging: Surveying consumers' attitude towards selected cosmetic brands. Economics and Sociology, 3 (1), 87-103.

Javed, S., \& Javed, S. (2015). The impact of product's packaging colour on customers' buying preferences under time pressure. Marketing and Branding Research, 2 (1), 4 - 14.

Karimi, P., Mahdieh, O., \& Rahmani, M. (2013). The study of the relationship between packaging elements and purchase behavior. Interdisciplinary Journal of Contemporary Research in Business, 5 (3), 281 - 295.

Khan, A. (2015). A study of influence of packaging on women skincare consumers in Jabalpur city. SUMEDHA Journal of Management, 4(2), 68 - 82.

Lee, S., \& Hoffman, K. (2016). Wrap-attack pack: Product packaging exercise. Marketing Education Review, 26 (1), $14-19$.

Lo, S.C., Tung, J., \& Huang, K.P. (2013). Customer perception and preference on product packaging. International Journal of Organizational Innovation, 9 (3), 3 - 15.

Magnier, L., Schoormans, J., \& Mugge, R. (2016). Judging a product by its cover: Packaging sustainability and perceptions of quality in food products. Food Quality and Preference, 53(1), 132 - 142.

Mohebbi, B. (2014). The art of packaging: An investigation into the role of colour in packaging, marketing, and branding. International Journal of Organisational Leadership, 3 (2), 92 - 102.

Neubauer, R. (1973). Packaging: The contemporarymedia. New York: Van Nostrand Reinhold. 
Pennning, A. (2012). The ink is the thing: Determining a cohesive packaging strategy. Global Cosmetic Industry. Retrieved from https://www.gcimagazine.com/

Pennning, A. (2014). Engaging innovation in beauty packaging. Global Cosmetic Industry. Retrieved from https://www.gcimagazine.com/

Roberge, D. (2016, October 27). What does your package color mean to consumers? Retrieved from https://www.industrialpackaging.com/blog/package-design-color-for-the-consumer

Rundh, B. (2005). The multi-faceted dimension of packaging: Marketing logistic or marketing tool ? British Food Journal, $107(9), 670$ - 684.

Rundh, B. (2013). Linking packaging to marketing: How packaging is influencing the marketing strategy. British Food Journal, $115(11), 1547-1563$.

Rundh, B. (2016). The role of packaging within marketing and value creation. British Food Journal, 118 (10), $2491-2511$.

Shekhar, S. K., \& Raveendran, P. T. (2013). Chocolate packaging and purchase behaviour: A cluster analysis approach. Indian Journal of Marketing, 43 (6), 5 - 14. doi:10.17010/ijom/2013/v43/i6/36388

Silayoi, P., \& Speece, M. (2007). The importance of packaging attributes: A conjoint analysis approach. European Journal of Marketing, 41(11/12), 1495 - 1517.

Simmonds, G., \& Spence, C. (2016). Thinking inside the box: How seeing products on, or through, the packaging influences consumer perceptions and purchase behaviour. Food Quality and Preference, 62, 340 - 351.

Simms, C., \& Trott, P. (2010). Packaging development: A conceptual framework for identifying new product opportunities. Journal of Marketing Theory, 10 (4), 397-415.

Wardy, W., Chonpracha, P., Chokumnoyporn, N., Sriwattana, S., Prinyawiwatkul, W., \& Jirangrat, W. (2017). Influence of package visual cues of sweeteners on the sensory - emotional profiles of their products. Journal of Food Science, 82 (2), 500 - 508.

Yang, D., \& Lee, C. (2016). In-store promotional mix and the effects on female consumer buying decisions in relation to cosmetics products. International Journal of Management, Economics and Social Sciences, 5 (2), $35-56$. 


\section{About the Authors}

Nada Bahgat Abdelazim Mohamed (M.Sc) researches and teaches advertising and marketing at the graduate level. Previously, she was appointed as Lecturer at MSA University (Egypt). Her interests include consumer buying behaviour and packaging design.

Dr. Irene García Medina holds Ph.D.s in Marketing (University of Sophia - Antipolis, France) and International Relations (University of Vienna, Austria). Currently, she is a Lecturer in Marketing at the Caledonian University of Glasgow (UK). Her interests include mobile marketing and digital marketing. She has given lectures and has conducted seminars and workshops in the field of marketing and advertising in several countries.

Dr. Zahaira González Romo holds a Ph.D. in Advertising and Public Relations from the Autonomous University of Barcelona, Spain. Currently, she is a Lecturer of Advertising and Public Relations at the Universitat Internacional de Catalunya. Her interests include digital communication, social media, and e-branding. She has published numerous articles and books in these areas. 